\title{
BREVE REFERENCIA A LA HISTORIA DE LA PRESCRIPCIÓN DE LAS INFRACCIONES PENALES. ESPECIAL CONSIDERACIÓN DE LA PROBLEMÁTICA SURGIDA EN EL DERECHO ROMANO A TRAVÉS DE DOS APORTACIONES FUNDAMENTALES
}

FÉliX M. a PEDREIRA GonzÁlez

Doctor en Derecho

Hoy, que ya comienza a advertirse el riesgo de que los avances en la tecnología forense, así como la aparentemente novedosa tendencia a la disminución derechos, libertades y garantías individuales, socaven aspectos de la ley vinculados al tiempo y plasmados en las normas sobre prescripción de infracciones penales ${ }^{1}$, no resulta inconveniente indagar en el pasado más o menos remoto, pero esta vez no para reavivar infracciones penales de tiempos lejanos, sino para poner de manifiesto la importancia de la prescripción del delito, el que "esas normas, como suele ocurrir con los preceptos generalmente aceptados, responden a una prudente sabiduría» ${ }^{2}$, y las ideas perversas y atávicas que se encuentran detrás de su negación, que en no pocas ocasiones nos las tratan de "vender» en la actualidad bajo una falsa faz de novedad, progresismo y modernidad.

El tiempo constituye un fenómeno natural que tiene y ha de tener una influencia decisiva en las diferentes ramas del Derecho. Una de las manifestaciones más importantes de esta influencia del tiempo en el Derecho, desde el punto de vista de sus efectos, es la institución de

1 Sobre estos riegos, cfr. el artículo de ScotT Turow, « ¿Culpable hasta la eternidad?", en diario El Mundo, lunes 16 de abril de 2007, págs. 4 y 5.

2 Scotr TuRow, "¿Culpable hasta la eternidad?», cit., pág. 5. 
la prescripción, que da lugar a la adquisición o pérdida de derechos y potestades por el transcurso del tiempo. Siempre ha constituido para mi una grata sorpresa observar que la institución de la prescripción, incluso en el ámbito de las infracciones penales, es una constante histórica, pudiendo encontrarse, incluso, en las etapas más remotas del Derecho Criminal, pues ello viene a poner de manifiesto que la exigencia de seguridad, la cesación de la incertidumbre, de la zozobra, de la inquietud, del desasosiego y, en definitiva, la necesidad de que no se prolonguen de forma indefinida las situaciones jurídicas expectantes vendría a ser algo inherente al ser humano, frente a lo que el Derecho nunca ha podido cerrar los ojos. En efecto, el Ordenamiento jurídico no puede dar las espalda ni a las necesidades más básicas del individuo, ni a su dignidad, y desde luego no resultaría acorde con la dignidad del ser humano la ausencia de limitación temporal del poder punitivo del Estado o, si se prefiere, la posibilidad de estar el resto de nuestra vida perseguidos y sujetos a la incertidumbre de la amenaza del Estado. Y lo cierto es que el Derecho, posiblemente en unos casos por razones más honorables que en otros, lleva desde tiempo inmemorial reconociendo la prescripción de las infracciones penales, con contadas excepciones.

Aunque algunos autores se inclinan por considerar que el origen de la prescripción del delito se encuentra en el Derecho Romano ${ }^{3}$, existen datos que apuntan a que ya en la Grecia clásica se conoció esta institución. Sirven de apoyo a esta teoría determinados textos atribuidos a Demóstenes y Lisias, de los que se deduce, con poco margen para las dudas, que los griegos admitieron la prescripción del delito, excepto para algunos supuestos imprescriptibles ${ }^{4}$. En el Dere-

${ }^{3}$ Cfr. Manzini, V. Trattato di Diritto Penale italiano, T. II, 5. a edición, Torino, 1986, pág. 523; VIADA LÓPEZ-PUIGCERVER, C. La prescripción de las acciones y el perdón de los delitos, Madrid, 1949, pág. 14.

${ }^{4}$ Cfr. Loening, R. "Die Verjährung», en Vergleichende Darstellung des Deutschen und Ausländischen Strafrechts, Allgemeiner Teil, I Band, Berlín, 1908, pág. 390, nota 5; Pessina, E. Elementos de Derecho Penal, trad. Hilarión González del Castillo, $3 .^{a}$ edición, Madrid, 1919, pág. 749; con mayor amplitud, Treude, F. Die Verjährung nach Reichsstrafgesetzbuch, Inaugural-Dissertation zur Erlangung der Doktorwürde der Hohen Juristenfakultät der Ruperto Carola zu Heidelberg, Heidelberg, 1908, pág. 13 y ss. El estudio de este último autor pone de manifiesto que el Derecho Ático conocía una prescripción del delito ya en época de Lisias (probablemente 459 a 378 a.C). Ello

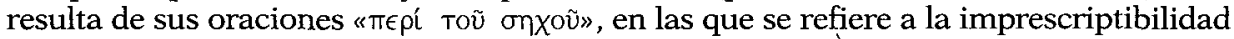

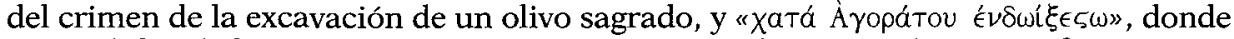
Lisias defiende la opinión de que un crimen como el presente (Agoratus fue acusado del asesinato de varios ciudadanos) no puede someterse a prescripción. Estos pasajes justifican la presunción de que en aquella época la prescripción en el Derecho Penal ya era la regla, porque de no ser así, no se comprendería la razón por la que Lisias re- 
cho Romano los datos que se conservan sobre la prescripción del delito resultan insuficientes y no permiten reconstruir con exactitud su estructura y evolución a través de las diferentes etapas. Ello ha determinado que ésta sea una cuestión escasamente tratada por los especialistas y muy discutida por aquellos que han abordado su problemática, entre los que destacan E. VOLTERRA y J.A.C THOMAS, cuyos artículos, que representan las dos posiciones fundamentales en esta materia, se adjuntan traducidos a continuación de esta exposición. No obstante, trataremos de efectuar una breve síntesis de la problemática planteada y de principales opiniones doctrinales.

Ciertamente nos encontramos ante una cuestión compleja y lo único que parece que puede afirmarse con suficiente seguridad es que la prescripción de las infracciones penales terminó por consolidarse como principio general en el Derecho Romano post-clásico, con la excepción de algunos delitos imprescriptibles. Es generalmente admitido que durante el periodo republicano (siglos $\mathrm{V}$ a I a.C.) no se conoció en Roma la prescripción del delito ${ }^{5}$. VolTERRA, que probablemente sea el autor que más ha profundizado en la cuestión, apoya esta hipótesis en los siguientes argumentos: por una parte, señala que en los numerosos procesos que se desarrollan bajo la República no se encuentra una sola vez apuntada la posibilidad de invocar la prescripción temporal, aludiendo como significativo en este sentido al ejemplo de Cayo Rabirio (que fue llevado a juicio después de 37 años de haber cometido el delito -Cicerón. Pro Rabirio, cap. IX-). Por otra parte, también considera de gran valor el argumento paralelo que puede extraerse del sistema de las obligaciones en el ámbito del Derecho privado, pues la obligación romana y las antiguas acciones civiles eran imprescriptibles y mantienen esta característica durante un largo periodo de tiempo. Ahora bien, como manifiesta el mencionado autor, la obligación romana tiene sus orígenes en el Derecho penal, sus fuentes primitivas son los delitos y sólo en un periodo histórico posterior se separa de ellos definitivamente, asumiendo un carácter propio. No hay quien deje de ver en este principio de la imprescriptibilidad de las obligaciones un indicio significativo de que

salta tan enfáticamente su opinión contraria a la prescripción en el último caso, si no es porque quería defender la necesidad de una excepción a la regla. Si no se conocía la prescripción, no se hubiera requerido ninguna palabra. De la oración de Demóstenes

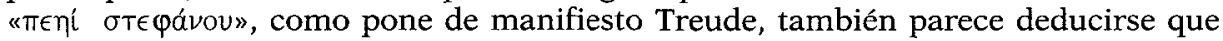
para ciertos actos de los que fue acusado existía prescripción, aunque no se dice cuáles eran estos.

${ }^{5}$ Cfr. Mommsen, T. Derecho Penal Romano, trad. P. Dorado, Bogotá, 1976, pág. 308; VOLTERRA, E. "Intorno alla prescrizione dei reati in diritto romano", en Bullettino dell'Istituto di Diritto Romano Vittorio Scialoja, XXXVII, 1929, págs. 64 y ss. 
aquel debió ser el concepto originario en materia de delitos, es decir, que el transcurso del tiempo no influía en la punición del hecho delictivo. Otra prueba que encuentra citado romanista es la normal transmisibilidad de las actiones poenales, en virtud de la cual, en los herederos del sujeto pasivo del delito, siempre perduraba la acción contra el culpable, lo cual confirma que el elemento tiempo, originariamente, no tenía importancia a tales efectos, ni el principio podía ser distinto para los crimina publica ${ }^{6}$.

Todo parece apuntar a que en los primeros tiempos del Imperio tampoco se admitió esta institución como principio general, sino tan solo en algunos supuestos muy puntuales, como lo fue el caso de la «Lex Iulia de adulteriis coercendis» —año 18 a. C.- , en virtud de la cual la acusación por adulterio, estupro o lenocinio sólo podía ejercitarse durante el plazo de cinco años ${ }^{7}$. Asimismo, la mayoría de los especialistas admiten que en tiempos de Diocleciano y Maximiano se fijó un plazo general de veinte años, del que sólo quedaron exceptuados algunos delitos sometidos al plazo de cinco años, como el adulterio, y ciertos delitos imprescriptibles, como el parricidio, la apostasía y la suposición de parto ${ }^{8}$. Esta postura se apoya en una disposición atribuida a Diocleciano y Maximiano, cercana al año 293 d. C., en la que se señalaba: "Querella falsi temporalibus praescriptionibus non excluditur nisi viginti annorum exceptione, sicut cetera quoque fere crimina» (Ad legem Corneliam de falsis). Ello ha conducido a la mayoría de los autores a considerar que en aquel momento (siglo III d. C.) ya existía un plazo general de prescripción de veinte años. Sin embargo, VoLTERRA, por medio de un riguroso análisis del contexto legislativo de aquel periodo, atribuye esta innovación a Justiniano, estimando que la declaración contenida en dicha disposición se debió a la posterior inserción por parte de los compiladores de Justiniano de una frase que cambia profundamente el texto y el significado originario de la ley ${ }^{9}$. Mommsen, por su parte, aunque admite la existencia de la prescripción de veinte años, no fija la época en que tal norma fue dictada ${ }^{10}$.

"Cfr. VolterRa, E. «Intorno alla prescrizione dei reati in diritto romano», ob. cit., págs. 64 y ss.

7 Cfr. Mommsen, T. Derecho Penal Romano, ob. cit., pág. 308; Volterra, E. «Intorno alla prescrizione...», ob. cit., págs. 62 y 63.

8 Cfr. Mommsen, T. Derecho Penal Romano, ob. cit., pág. 309; Robinson, O. F. The Criminal Law of Ancient Rome, London, 1995, pág. 21; THOMAS, J. A. C. «Prescription of Crimes in Roman Law", en Revue internationale des droits de l'antiquité, IX, 1962, págs. 417 y ss, y la bibliografía allí citada.

9 VOLTERRA, E. «Intorno alla prescrizione dei reati...», ob. cit., págs. 57 y ss.

10 Mommsen, T. Derecho Penal Romano, ob. cit., págs. 308 y 309. 
Para VolTerra, tampoco la tesis defendida por la doctrina mayoritaria, consistente en señalar que el término de veinte años vigente desde la época de Diocleciano fue alargado a una cifra superior (a la praescriptio triginta annorum o, incluso, según algunos, a la praescriptio cuadraginta annorum), encuentra ninguna confirmación en los textos romanos y bizantinos y por ello, a su juicio, resulta totalmente arbitraria y carente de cualquier base segura: «Ninguna de las constituciones emanadas de los emperadores en el Bajo Imperio, para sancionar y regular la institución de la praescriptio, muestra que esta institución se pudiera aplicar a los juicios penales en general. Si, en efecto, la L. 4 C. de praescr. 7, 39 de Anastasio (en la que se basan los que defienden la prescripción de cuarenta años) no alude expresamente a los delitos, ese mismo silencio parece encontrarse en la precedente L. 3. eod. de Onorio y Teodosio, que introduce en el Derecho Romano la prescripción de treinta años». Tampoco los otros textos ( $v$. g. la Novela de Valentiniano de episcopali iudicio), citados para demostrar que en el bajo Imperio se aplicaba a los delitos el término de treinta años, ofrecen para este autor una prueba segura ${ }^{11}$.

En el primitivo Derecho germánico, por el contrario, esta institución apenas fue conocida, aunque parece que en las antiguas costumbres nórdicas pueden encontrarse limitaciones temporales al derecho de venganza privada ${ }^{12}$. Con mayor amplitud se reconoció esta institución por el Derecho visigodo, que estableció en el Liber Iudiciorum un plazo general de treinta años ${ }^{13}$. En las fuentes del antiguo Derecho penal canónico se encuentra un pasaje de los Decretales que señala la prescripción romana de veinte años ${ }^{14}$. Con el renacimiento del Derecho Romano se reproducen entre los intérpretes sus disposiciones respecto a la prescripción penal, aunque la imprescriptibilidad excepcional que contemplaba el Derecho Romano se fue extendiendo a los delitos más graves, como el asesinato, el duelo y el delito de lesa majestad ${ }^{15}$. A lo largo de la Edad Media, la regla de la prescripción de las infracciones fue acogida, con mayor o menor amplitud, en muchos lugares, sobre todo en los territorios

11 Cfr. Volterra, E. "Intorno alla prescrizione dei reati...», ob. cit., págs. 71 y 72.

12 Cfr. Loening, R. «Die Verjährung», ob. cit., pág. 384.

13 Liber iudiciorum X, 2, 3. La mencionada disposición se corresponde con la contemplada en la ley III, Título II, Libro X del Fuero Juzgo.

${ }^{14}$ Decret. Greg., lib. II, tit. 25 de excep., c. 6.

15 Cfr. ManzinI, V. Trattato di Diritto Penale italiano, T. III, ob. cit., págs. 525 y ss; Moazzami, H. La prescription de l'action pénale en droit français et en droit suisse, Montreux, 1952, pág. 29; PESsina, E. Elementos de Derecho Penal, ob. cit., pág. 750. 
que hoy forman parte de Italia ${ }^{16} \mathrm{y}$, desde finales del medievo, en Francia $^{17}$.

No obstante, hasta finales del siglo XVIII la prescripción criminal no pasó de ser una figura con un ámbito de aplicación un tanto limitado, carente de reglas fijas y principios estables, excluida por lo general para los delitos más graves, inconcebible cuando ya existía una sentencia condenatoria y sometida, en muchos casos, a ciertas condiciones, como que el delincuente no hubiera cometido un nuevo delito, ni se hubiera fugado del país, ni hubiera gozado del provecho de su acto, etc. Realmente fue la codificación penal francesa la que en este caso, como en muchos otros, dio el impulso decisivo a la institución.

El Código Penal francés de 25 de septiembre -6 de octubre- de 1791, en su Título VI, contenía por primera vez un conjunto ordenado y sistemático de disposiciones en materia de prescripción penal, que sirvieron de base a la regulación posterior del Código de Instrucción Criminal. Examinemos brevemente los principios sentados por esta legislación: 1.-La cuestión decisiva en la prescripción el mero transcurso del tiempo, sin otros condicionamientos añadidos, salvo el hecho de que en el plazo previsto no se hubiera llevado ninguna persecución. 2.-Se admitía la prescripción para todos los delitos,

${ }^{16}$ Cfr. Manzini, V. Trattato di Diritto Penale italiano, T. III, ob. cit., págs. 525 y ss.

17 Cfr. GaRraud, R. Traité théorique et pratique du droit pénal français, T. II, 3. ${ }^{\mathrm{a}}$ edición, Paris, 1914, pág. 546; MoAzzaMI, H. La prescription de l'action pénale..., ob. cit., págs. 27 y 28 . En nuestro Derecho, aunque no puede descartarse la hipótesis de que esta institución fuese reconocida como principio general en algunos lugares, a través de la vigencia del Fuero juzgo o de la costumbre, los restantes textos legislativos medievales consultados no contemplaron la prescripción del delito, salvo en casos muy puntuales. En las Partidas de Alfonso X El Sabio, aunque se estableció como principio general la imprescriptibilidad de las infracciones (Partida VII, Tít. I, Ley VII), es posible encontrar algunos supuestos en los que se admitió la prescripción del delito. Así, las falsedades prescribían a los veinte años, a contar desde el día en que se hubiera cometido la infracción (Partida VII, Tít. VII, Ley V). Para el adulterio se estableció el plazo de cinco años, también a contar desde el día en que se hubiera cometido el delito, salvo que se hubiera hecho uso de la fuerza, en cuyo caso el plazo era de treinta años (Partida VII, Tít. XVI, Ley IV); este régimen también se aplicaba al incesto (Partida VII, Tít. XVIII, Ley II) y al estupro (Partida VII, Tít. XIX, Ley II). Para las injurias se fijaba el término prescriptivo de un año, a contar desde el día de su comisión (Partida VII, Tít. IX, Ley XXII); cfr., Los códigos españoles, concordados y anotados, Madrid, 1849. Este reconocimiento excepcional de la prescripción del delito, con arreglo a las Partidas de Alfonso X, fue la tónica general en nuestro Derecho hasta el inicio de la codificación penal española (cfr. BERNI, J. Práctica criminal, Valencia, M.DCC.XLIX, reimpresión por editorial Civitas, Madrid, 1995, págs. 8, 24 y 44; GuTiÉRREZ FERnÁndeZ, B. Examen histórico del Derecho Penal, Madrid, 1866, págs. 106 y ss, y en particular, págs. 109, 169, 177, 180 y 189). 
sin contemplar la figura de la imprescriptibilidad. 3.-El plazo de prescripción del delito era de tres años, cuando en ese intervalo no se hubiera llevado a cabo ninguna persecución (artículo 1), y de seis años en los restantes supuestos (artículo 2). 4.-Los plazos comenzaban a correr desde el día en que la existencia del delito hubiera sido conocida o legalmente constatada (artículo 2). 5.-Además de la prescripción del delito se contemplaba la prescripción de la pena, para la que se establecía un plazo de veinte años a contar desde la fecha del juicio ${ }^{18}$.

El Código del 3 de Brumario del año IV, sin apenas modificaciones, reproducía en sus artículos 9 y 10 el mismo sistema del Código de $1791^{19}$. Por su parte, el Código de Instrucción Criminal de 26 de diciembre de 1808 regulaba la prescripción del delito en los artículos 637 y siguientes, ubicados dentro del Capítulo V del Título VII. Aunque esta regulación se inspiraba en la de los Códigos precedentes, atribuyendo el papel decisivo al transcurso del tiempo y admitiendo la prescripción de todos los delitos y penas, también contenía importantes innovaciones, sobre todo en lo relativo a la proporcionalidad de los plazos prescriptivos. Así, los delitos castigados con pena de muerte o pena aflictiva o infamante prescribían transcurridos diez años, a contar desde el día en que el crimen se hubiera cometido, si en este intervalo no se hubiera verificado ningún acto de instrucción o de persecución. Si se hubiera verificado en este intervalo algún acto de instrucción o persecución no seguidos de juicio, el plazo de prescripción era de diez años a contar desde el último acto, excluyendo a las personas que no hubieran sido implicadas en el mismo (artículo 637). Si se trataba de un delito castigado correccionalmente, la duración de la prescripción se reducía a tres años (artículo 638). En las contravenciones de policía el plazo era de un año (artículo $640)^{20}$.

El Código de Instrucción Criminal francés de 1808 ha servido de inspiración a la inmensa mayoría de las legislaciones penales europeas. Sin embargo, las reticencias manifestadas hacia la institución por algunos de los máximos exponentes del pensamiento ilustrado ${ }^{21}$,

18 Cfr. Moazzami, H. La prescription de l'action pénale..., ob. cit., págs. 40 y 41.

19 Cfr. Moazzami, H. La prescription de l'action pénale..., ob. cit., págs. 42 y 43.

20 Cfr. Moazzami, H. La prescription de l'action pénale..., ob. cit., págs. 44 y ss.

21 Para Beccarta las leyes debían «fijar un cierto espacio de tiempo tanto para la defensa del reo cuanto para las pruebas de los delitos, y el juez vendría a ser legislador si estuviese a su arbitrio determinar el tiempo necesario para probar un delito. Igualmente aquellos delitos atroces que dejan en los hombres una larga memoria, si están probados, no merecen prescripción alguna en favor del reo que se ha sustraído con la 


\section{tuvieron su reflejo en las legislaciones de finales del siglo XVIII y principios del XIX, sobre todo en las regiones que hoy forman parte de}

fuga; pero los delitos leves y no bien probados deben librar con la prescripción la incertidumbre de la suerte de un ciudadano, porque la oscuridad en que se hallan confundidos por largo tiempo quita el ejemplo de impunidad, quedando en tanto al reo en disposición para enmendarse" (BECCARIA, C. De los delitos y de las penas (con el comentario de Voltaire), Madrid, 1997, Capítulo XXX, págs. 92 y 93). Semejante distinción, aunque con otros argumentos, formulaba el padre del utilitarismo, JEREMY BENTHAM, al afirmar que esta institución podía «tener lugar sin inconveniente en los delitos de temeridad y de negligencia, delitos que resultan de una falta exenta de mala fe. Después del accidente se ha visto la circunspección del delincuente, y ya no es un hombre temible. Su perdón es un bien para él, y no es un mal para nadie. Se puede también extender la prescripción a los delitos no consumados, a tentativas que han fallado. El delincuente en el intervalo ha sufrido en parte la pena; porque temerla ya es sentirla. Por otra parte se ha abstenido de delitos semejantes; se ha reformado a sí mismo, se ha hecho un miembro útil a la sociedad, y ha recobrado su salud moral sin usar del remedio amargo que la ley le había preparado para curarle. Pero si se tratara de un delito mayor, por ejemplo, de una adquisición fraudulenta, capaz de hacer rico a un hombre, de una poligamia, de un estupro violento, de un robo con fuerza armada, sería odioso, sería funesto, el permitir que pasado un cierto tiempo pudiese la maldad triunfar sobre la inocencia. Fuera de transacciones con malvados de esta clase, y que la espada vengadora de la ley esté siempre suspendida sobre su cabeza. El espectáculo de un delincuente que protegido por las leyes que ha violado, goza en paz del fruto de su delito, es un cebo para los malhechores, un objeto de dolor para los hombres de bien, y un insulto público a la justicia y a la moral» (BENTHAM, J. Tratados de legislación civil y penal, edición preparada por Magdalena Rodríguez Gil, Madrid, 1981, pág. 300). Mucho más favorable hacia la institución se mostraba FILANGIERI, cuando señalaba: «Finalmente, el último sello que la Ley ponía a la libertad del ciudadano, era la determinación de cierto tiempo, pasado el cual quedaba prescrito el derecho de acusar. Si para asegurar la propiedad se debió establecer cierta prescripción para las acciones civiles, parecía muy justo que para asegurar la vida, el honor y la libertad del ciudadano, se estableciese otra para las acusaciones criminales. No hay cosa más difícil que defenderse de una acusación cuando se intenta muchos años después del delito. El tiempo, que borró de la memoria las circunstancias que le acompañaron, priva al acusado de los medios de justificarse, y ofrece al calumniador astuto un velo para cubrir sus meditadas imposturas... La prescripción de las acusaciones también es un remedio que se debería adoptar. La de los romanos era demasiado larga, pues hemos observado que en muchos delitos era de veinte años. En Inglaterra es de tres (El estat. 7. de Guillermo III, cap. 3. prohibe perseguir en juicio los delitos de cualquier especie en el caso que el libelo de la acusación no se haya presentado dentro de los tres años después de cometido el delito. Solamente se exceptúan los atentados contra la vida del Rey). Es mucho más difícil defenderse de una calumnia después de veinte años que después de pasados tres, y por esta razón debería preferirse el método de los ingleses» (FILANGIERI, C. Ciencia de la Legislación, Trad. Jaime Rubio, tercera edición, T. IV, Madrid, 1882, págs. 23-24 y 71-72). ANSELM VON FEUERBACH, por su parte, manifestaba su escepticismo en esta materia, al afirmar que «difícilmente la prescripción del crimen tenga otra razón que la máxima de los doctrinarios romanos, de ampliar y redondear el sistema mediante la aplicación analógica de cierto principio jurídico. De la prescripción extintiva de la acción se deriva la consecuencia puramente lógica y también natural de la prescripción extintiva de la acusación (accusationum). Lo que pueda decirse de los fundamentos jurídicos de su introducción en el sentido 
Italia, Austria y Alemania ${ }^{22}$. En este sentido, no era infrecuente que la prescripción se negase para los delitos más graves y que se encontrase sometida a las más diversas condiciones, como el buen comportamiento del autor, la constatación de que no había huido o la satisfacción de las responsabilidades civiles ${ }^{23}$. Incluso en Austria, donde ya se había admitido esta institución, se suprimió por completo en el año 1787, aunque el Código General Imperio Austriaco de 1803 volvió a reconocerla, no sin algunas limitaciones ${ }^{24}$.

Pero tras esta reticencia inicial es preciso convenir que la influencia de la legislación revolucionaria francesa también terminó por ser ostensible en estos lugares ${ }^{25}$. En este sentido, tanto el Código Penal italiano de 1889, como el Código de la Confederación Alemana del Norte de 1870 y el del Imperio Alemán de 1871, se inspiraban en el Derecho francés y ya contemplaban tanto la prescripción del delito como la prescripción de la pena ${ }^{26}$. En líneas generales este sistema ha sido acogido favorablemente por la doctrina y la legislación posterior, con la excepción de la etapa del nacionalsocialismo alemán, cuya legislación se opuso a esta institución, de forma coherente con su concepción autoritaria del Estado y del Derecho Penal ${ }^{27}$. En una tesis doctoral de aquél periodo podía leerse: «Nuestro ordenamiento jurí-

político o material es una conjetura fundada y no probada» (FEuERBACH, A.v. Tratado de Derecho Penal común vigente en Alemania, traducción de la $14 .^{a}$ edición alemana (1847) por Zaffaroni, E. R. y Hagemeiner, I., Buenos Aires, 1989, pág. 88).

22 Cfr. FreiHerR VON STACKELBerG, C. «Verjährung und Verwirkung des Rechts auf Strafverfolgung", en Festschrift für Paul Bockelmann zum 70. Geburtstag, München, 1979, pág. 759; LOENING, R. «Die Verjährung», ob. cit., págs. 411 y ss; MaNZINI, V. Trattato di Diritto Penale italiano, T. III, ob. cit., págs. 527 y ss; MAYER, H. Strafrecht, Allgemeiner Teil, Stuttgart, 1953, pág. 353; von LIszT, F. Tratado de Derecho Penal, trad. Ji-

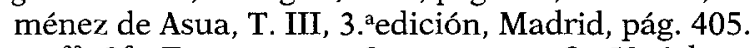

${ }^{23}$ Cfr. FreinerR von StACKelBerg, C. "Verjährung und Verwirkung des Rechts auf Strafverfolgung», ob. cit., pág. 760; LoENING, R. "Die Verjährung», ob. cit., págs. 414 y ss; LoREnZ, M. Die Verjährung in der deutschen Strafgesetzgebung, München und Berlin, 1955, pág. 80.

${ }^{24}$ Se exigía que el sujeto no hubiera obtenido ningún provecho del delito, que se hubiese esforzado en indemnizar a la víctima y que no hubiera huido del país ni cometido otro delito durante el tiempo de la prescripción (cfr. LOENING, R. «Die Verjährung», ob. cit., pág. 414).

${ }_{25}$ Cfr. FreiherR von Stackelberg, C. «Verjährung und Verwirkung des Rechts auf Strafverfolgung», ob. cit., pág. 760; LoENING, R. «Die Verjährung», ob. cit., págs. 425 y ss.

26 Cfr. Manzini, V. Trattato di Diritto Penale italiano, T. III, ob. cit., pág. 527 y ss; Pessina, E., Elementos de Derecho Penal, ob. cit., págs. 751 y 752; von LiszT, F. Tratado de Derecho Penal, T. III, ob. cit., págs. 405 y 406.

27 Cfr. LoREnZ, M. Die Verjährung in der deutschen Strafgesetzgebung, ob. cit., págs. 32 y ss. 
dico tiene que servir en primera línea a la conservación de la comunidad popular. El individuo no puede ser el centro de las preocupaciones legales, sino el pueblo. El valor más alto del Derecho penal es la comunidad popular... La tarea del Derecho penal es, como hemos reconocido, proteger las bases vitales de la comunidad popular, su ordenamiento jurídico. Esta protección se extiende a todos los bienes populares, tanto ideales como materiales, al Estado como forma organizativa del pueblo $\mathrm{y}$, a parte de eso, también a los particulares miembros de la comunidad en virtud de su valor para la totalidad. Para configurar esa protección de manera efectiva tienen que ser destruidas las fuerzas contrarias a la comunidad. Ha de satisfacerse además la sensación punitiva que había sido provocada en la comunidad por la ruptura del ordenamiento jurídico. En la destrucción de esas fuerzas está al mismo tiempo la advertencia a todos los demás de guardar y respetar el ordenamiento jurídico. En estos tres criterios de la destrucción, de la sanción y de la advertencia residen los fines principales de la pena... Tras esta fijación de los fines del Derecho penal y de la pena, la fundamental contestación de la pregunta por el mantenimiento del instituto de la prescripción penal, tal y como está regulado en el Derecho vigente, no puede ser dudosa: ... El interés de la comunidad popular exige en todo tiempo destruir las fuerzas que a ella se oponen.... ${ }^{28}$.

Teniendo en cuenta lo anterior, es fácil deducir que la negación de la prescripción penal pose, al menos en gran medida, una raíz autoritaria, que justifica menoscabo de los derechos y garantías individuales en favor de unos pretendidos intereses sociales y colectivos que se hallan al margen del individuo y no dudan en sacrificarlo si fuera preciso. Ciertamente, no es una casualidad que los retrocesos más notorios en materia de prescripción penal se encuentren estrechamente vinculados a sistemas esencialmente antiindividualistas y autoritarios, y que sus grandes avances hayan venido de la mano de la legislación revolucionaria francesa.

${ }^{28}$ Hasselberg, A. Zur Frage der Verjährung im kommenden Strafrecht, InauguralDissertation zur Erlangung der Doktorwürde der Hohen Juristischen Fakultät der Friedrich-Alexanders-Universität zu Erlangen, Erlangen, 1935, pág. 27 y ss. 